\title{
A questionnaire to compare lecturers' and students' higher education research integration experiences
}

\author{
Author(s) \\ Griffioen, D.M.E. \\ DOI
}

10.1080/13562517.2019.1706162

Publication date

2022

Document Version

Submitted manuscript

\section{Published in}

Teaching in Higher Education: Critical Perspectives

Link to publication

Citation for published version (APA):

Griffioen, D. M. E. (2022). A questionnaire to compare lecturers' and students' higher education research integration experiences. Teaching in Higher Education: Critical Perspectives, 27(2), 185-200.

https://doi.org/10.1080/13562517.2019.1706162

It is not permitted to download or to forward/distribute the text or part of it without the consent of the author(s) and/or copyright holder(s), other than for strictly personal, individual use, unless the work is under an open content license (like Creative Commons).

If you believe that digital publication of certain material infringes any of your rights or (privacy) interests,

please let the Library know, stating your reasons. In case of a legitimate complaint, the Library will make the material inaccessible and/or remove it from the website. Please contact the library:

https://www.amsterdamuas.com/library/contact/questions, or send a letter to: University Library (Library of the University of Amsterdam and Amsterdam University of Applied Sciences), Secretariat, Singel 425, 1012 WP Amsterdam, The Netherlands. You will be contacted as soon as possible. 
A Questionnaire to Compare Lecturers' and Students' Higher Education Research

Integration Experiences

Didi M.E. Griffioen

Research group Higher Education Research \& Innovation

Amsterdam University of Applied Sciences

D.M.E.Griffioen@hva.nl

This manuscript as was initially submitted for review and is now after review published as:

Didi M.E. Griffioen (2020) A questionnaire to compare lecturers' and students' higher education research integration experiences, Teaching in Higher

Education, DOI: 10.1080/13562517.2019.1706162

Link to published version 


\begin{abstract}
Students and lecturers share educational experiences, each in their role: Students as part of their learning context and lecturers as part of their work environment. But how much of their experiences are similar? A questionnaire was developed to provide insight into the experiences of research integration of undergraduate students $(\mathrm{N}=2,336)$ and lecturers $(\mathrm{N}=379)$. For measurements, the Research Attitudes in Vocational Education Questionnaire (RAVE-Q), and Experience in Research Integration scale were applied to the student survey design. For lecturers, all items of the student surveys were rephrased into items related to lecturers' perceptions of their students' attitudes and experiences. The findings show that students and lecturers share perceptions about the role of research in their related vocational field and about research integration. However, important cognitive and affective differences were found between students and lecturers regarding research practice. Implications for further research and educational design will be discussed.
\end{abstract}

Keywords: Higher Education, Research-teaching-nexus, Research Integration, Studentsas-partners, Questionnaire. 


\section{A Questionnaire to Compare Lecturers' and Students' Higher Education Research Integration Experiences}

The explicit integration of research and teaching has been introduced into the debates on higher education since the 1990s (Visser-Wijnveen, Van der Rijst, \& Van Driel, 2016). However, in many applied university settings, conducting research is still a relatively new endeavour (Griffioen \& De Jong, 2017). The integration of research into higher educational programmes has not yet been fully formalized. Even at research-intensive universities with rich research traditions, connections between research and educational programmes are still under development (Fung, 2017).

During the last decade, debates about the integration of research into educational programmes seem to have shifted from the question of 'Should we?' to 'How, what, and how far?' Due to the liquidity (Brew, 2006) or 'supercomplexity' of society (Barnett, 2000), universities take on the responsibility if providing research experiences for students as our future highly skilled professionals. Discussion has focused on how to bring students and meaningful research together through connected curricula (Fung, 2017) and research-based education (Gilardi \& Lozza, 2009). The number of colleagues advocating that research should not be integrated seems to be shrinking, even in applied universities (Griffioen, 2018a). Similar perspectives are presented in national policies (Karseth \& Solbrekke, 2016; Teichler, 2014). Nonetheless, those of us who teach still collectively wonder how to incorporate research into the daily practice of our students and whether we succeed in the eyes of our students.

A parallel development to research integration is the students-as-partners movement (Bovill, Cook-Sather, Felten, Millard, \& Moore-Cherry, 2016; Cook-Sather, 2014). Some of the 
same colleagues who are driving advocates of the research-teaching nexus (Healey \& Jenkins, 2015) are also important voices in the students-as-partners movement. Considering the researchteaching concept that 'students are kept too long out of the research game' (Brew, 2006), this is not surprising.

What is surprising, however, is that this combination of movements has not yet resulted in developing measurement instruments to compare lecturer and student perspectives of research integration, especially because this comparison of perspectives could both inform researchteaching discussion and serve the notions of students-as-partners advocates. However, so far an instrument that systematically considers both students' and lecturers' perceptions has not been developed, and this is an important omission. Considering that universities aim to integrate research into their higher education programmes, lecturers are an important carrier to achieve this aim (Schouteden, Verburgh, \& Elen, 2014; Visser-Wijnveen, Van Driel, Van der Rijst, Verloop, \& Visser, 2009). Asking lecturers what they perceive as successful integration of research and education can provide valuable insight in their perceptions as such. Additionally, lecturers' responses indicates reasons for fast of slow implementation and, consequently, higher education change. Furthermore, comparison between lecturers' and students' perceptions of research integration, including its personal importance to them, can provide important, practical guidelines for collaborative curricula designs.

So far, the tools to measure lecturers' perspectives of research integration have been mainly of a deep and qualitative nature (e.g. Brew, 2001; Griffioen \& De Jong, 2015b; Schouteden, Verburgh, \& Elen, 2011), while instruments to measure student perspectives have been sometimes of qualitative nature (Pitcher, 2011) but mostly quantitative in orientation. Current instruments focus on student experiences of research integration in general (Healey, 
Jordan, Pell, \& Short, 2010), at the semester level (Vereijken, Van der Rijst, De Beaufort, Van Driel, \& Dekker, 2016), and at the module level (Visser-Wijnveen et al., 2016). Although this difference in approach can be explained by the relative differences in lecturer and student sample sizes, it nonetheless implies that existing data on research integration cannot easily be compared between lecturers and students. When we aim to have students as our partners in how we integrate research into education, a comparison between the perspectives of both groups can provide critical information. Hence, the current manuscript aims to provide a measurement instrument that can be applied to both lecturers and students.

\section{Concepts Related to Experienced Research Integration}

The connection between research and teaching has multiple faces (Trowler \& Wareham, 2008). Previous studies have addressed four different foci of the connection between research and teaching (Brew, 2003; Smeby, 1998): in the perceptions and activities of students (Brew, 2003); in the intended, executed, or experienced curriculum (Barnett, 2012; Griffioen, Groen, \& Nak, submitted); in the tasks, competencies, and perceptions of faculty members (Åkerlind, 2008; Lopes, Boyd, Andrew, \& Pereira, 2014); and in local, national, and international policies and structures (Griffioen \& De Jong, 2017; Jenkins \& Healey, 2005). However, to make a comparison between students' and lecturers' perceptions, it is necessary to consider aspects that are within the perspective of students. Many students only grasp the tangible aspects of research integration (Visser-Wijnveen et al., 2016), although other aspects are possible (Neumann, 1992). For instance, from the perspective of the typical student, the intended and executed curriculum are abstract entities, which is very different from the experiences of lecturers who are often involved in curricula designing. On the other hand, the experienced curriculum is very real for both students and lecturers, and both groups develop perceptions of their experiences (Van den 
Akker, 2003). For our measurement instrument we included three perspectives: attitude to research of lecturers and students (which includes perceptions of research related to future professional practice); experience with research integration through activities (which can be curriculum-related or extracurricular); and the perception of the university context, which is framed as the experienced culture.

\section{Attitude towards Research}

Only a few instruments have been developed to measure attitudinal variables related to research integration. Attitude variables, such as perception, conception, and self-efficacy of research are important because they can influence the behaviour of students in their current and future work. The theory of reasoned action (Ajzen \& Fishbein, 2010) proposes that an individual's behavioural intentions depend on his or her perceptions of self-efficacy and the function of the tools provided. In the current setting, these aspects are related to the function of conducting research in professional practice and the confidence students feel in conducting research. The intention of professional higher education is that students' apply these skills in their future professional practice (Griffioen, 2018b). While the same balance between variables can be applied for lecturers' use of research in their own practice (Griffioen \& De Jong, 2015a), this study considers lecturers' perception of their students attitudes towards research, such as students' research self-efficacy.

Few studies to date have considered measuring the multiple dimensions of students' and lecturers' attitudes towards research. An exception is the study by Van der Linden, Bakx, Ros, Beijaard, and Van den Berg (2015) who considered attitudes toward research in teacher education students. Their findings showed that student teachers had a more positive attitude towards research after a second year introductory research course in which the origin of 
information was central. However, students' intention to use their new knowledge in their future teaching practice did not increase. Griffioen (2018b) transformed this work in teacher education into the generic Research Acceptance in Vocational Education Questionnaire (RAVE-Q) instrument, which was designed to measure students' attitudes towards research across disciplines and in their future professions. Her study showed that students' attitudes were more firmly related to their intention to use research in their future work than their experienced research integration or their perception of the university's research culture. Here, the instrument is transformed to also measure lecturers' perceptions of their students' attitudes towards research.

\section{Experienced Integration and University Culture}

Several studies have focused on a survey methodology to measure students' experienced research integration. Several (Spronken-Smith, Mirosa, \& Darrou, 2014; Verburgh \& Elen, 2011) based their approach on the original work designed by Healey et al. (2010). Combined, these studies present the current dominant line of reasoning, that students are motivated and stimulated by being involved in research activities but also experience a lack of teacher time and interest due to the academic focus on research (see also: Visser-Wijnveen et al., 2016). Additionally, Visser-Wijnveen (2016) constructed a questionnaire that aimed to capture students' perceptions of research integration at the course level. The instrument of Healey et al. (2010) was also used to develop an instrument measuring lecturers' views on research integration in their own university modules (Roseaux, Verachtert, Spooren, \& Van Petegem, 2014). A wider focus on students' notions of research was found in studies that focused on how students experienced their lecturers' research activities (Verburgh \& Elen, 2011) and students' 
perceptions of the quality of research in their education and in their university's research culture (Verburgh \& Elen, 2011; Visser-Wijnveen et al., 2016).

None of the instruments previously used was designed with the intention to compare perceptions of research integration of lecturers and students. Therefore, the current study aims to close this gap by providing a valid instrument for this comparison. Only then can lecturers and students work together towards higher education curricula design that aims to further integrate research. Additionally we aim to better understand the similarities and differences of lecturers' and students' perceptions on experienced research integration.

\section{Methods}

This study was conducted in a single university of applied sciences in the Netherlands. All students and lecturers were invited to participate in an online survey. In this study, only undergraduate students who filled out the complete questionnaire were included, resulting in a sample size of 2,339. For all student characteristics, see Table 1. For lecturers, this sample size was 379 .

\section{Measurements}

In line with the theoretical framework, three levels of measurements were included, which were based on previously applied and validated questionnaires for students. The combined questionnaire was previously adapted for students in a Dutch setting of higher professional education (Griffioen, 2018b).

The first level focuses on research attitudes and was measured by applying the RAVE-Q, which was developed by Griffioen (2018b) and based on the work by Van der Linden et al. (2015). The RAVE-Q includes the following scales: perceptions of research in profession, cognitive attitude towards research, positive affective attitude towards research, negative 
affective attitude towards research, self-efficacy towards research, importance of research, and intention to show research-related behaviour.

The second level focuses on experienced research activities by students as measured by the Research Experience scale by Verburgh and Elen (2011) and is distinguished by the scales to read and discuss research in class, to interact with researchers, and student as researcher.

The third level focuses on the research context of students and was measured by the application of three scales as developed for students by Griffioen (2018b): 'Research by My Lecturers', based on previous work by Verburgh and Elen (2011), as well as 'Quality of Research in My Education' and 'Research Culture', which were both derived from the combined work of Verburgh and Elen (2011) and (Visser-Wijnveen et al., 2016).

To compare lecturers' and students' perceptions of research integration, a new questionnaire with similar items and scales was developed for lecturers (for all items of the final scales, see Appendix A). Before providing the questionnaire to the large group, the newly developed items were reviewed by three individual colleagues for feedback through a think-aloud session with the aim of clarity of formulation, and items were adjusted accordingly. All items were measured by applying a 6-point Likert scale ranging from 1 (not at all applicable) to 6 (completely applicable).

\section{Analysis}

To arrive at a reliable questionnaire for both students and lecturers, the combined questionnaires included several analytic steps. First a factor analysis with oblique rotation was conducted on each included scale in SPSS 25. To explore the soundness of the scales and to develop a more economical questionnaire, items were included when meeting the following criteria: (a) to load at least .40 on a factor; (b) to not load more than .20 on another factor, (c) to 
not reduce the internal consistency of the scale based on the Cronbach's alpha. The internal consistency of scales was considered reliable with a Cronbach's alpha higher than .60. All others were excluded.

The construct validity was tested in a confirmatory factor analysis in Mplus 8, which was based on a balance between several fit indexes. The traditionally applied $p$ value is not a reliable measure with a large sample size, so a combination of the root mean square error of approximation (RMSEA), a parsimony-adjusted measure, and the Tucker-Lewis index (TLI) and the comparative fit index (CFI), both comparative indices, were applied and measured against a null model (Kline, 2011). Of these indexes, RMSEA was best in terms of model specification. A value equal to or greater than 0.90 is considered a good fit in the case of TLI and CFI. A RMSEA value equal to or less than 0.05 is used as an indication of close fit of the data with the assumed model, and less than .08 is considered an acceptable fit. Further, the aim of reaching a parsimonious model was taken into account, considering that the survey should also be applicable through SPSS only. The reliability of the final scales was then calculated through a recalculation of Cronbach's alpha.

After finding a proper construct validity, the content comparison between students and lecturers was analysed with ANOVA analyses in SPSS25. A more conservative $p$ value of .01 was applied to correct for family wise error rate (Tabachnick \& Fidell, 2007).

\section{Findings}

In this section, the findings on model fit and the development of the questionnaire are presented. Then the differences and similarities between students and lecturers on the different scales are explained.

\section{Model Fit}


The first two steps of the analysis were focused on reaching sufficient model fit. In the first step, factor and reliability analyses confirmed the proposed scales for students as found by Griffioen (2018b) for the combined data of lecturers and students. However, in the second step, to improve model fit across all factors, three items were removed for further analysis: two items from the perception on research scale and one item from the research culture scale, all of which were originally negatively formulated items. Additionally, the correlation between negative attitudes towards research and cognitive attitudes about research — to read and discuss research, the student as a researcher, and the importance of research-were reduced to zero. Finally, another item was removed from the attitude scale. All model changes in step two were based on modification indexes, which suggested it would have been possible to further improve the CFI and TLI; however, this would have resulted in a much less parsimonious model due to added covariances between items, which would be much more difficult to use in educational practice. So, we decided to be satisfied with the very close fit based on RMSEA $=0.45$ and the sufficient fit based on CFI $=.890$ and $\mathrm{TLI}=.882$.

All items contributed significantly to the related factors (scales) at $\mathrm{p}<.001$. For all scales, items and reliability measures see Appendix A. For the standardized correlations between scales, see Table 1.

<Insert Table 1 about here>

\section{Differences and Similarities Between Students and Lecturers Found}

The ANOVA resulted in several differences in perceived research integration between the current sample of students and lecturers. First, at the level of research attitudes, lecturers and 
students showed similar scores in their perceptions of research in their future professions, illustrated by a lack of significant differences. With a mean score of 4.6 , both students and lecturers considered research to be a relatively important part of student professional preparation. For all mean scores, see Appendix.

On all other aspects of the RAVE-Q, students and lecturers did show significant differences, with lecturers scoring, on average, higher on cognitive attitude towards research with $\mathrm{F}(\mathrm{df})=23,072(1) ; \mathrm{p}=.000$, and on the importance of research, with $\mathrm{F}(\mathrm{df})=10,484(1) ; \mathrm{p}=$ .001. Lecturers also scored higher on students' negative affection towards research, with $\mathrm{F}(\mathrm{df})=$ 139.273(1); $\mathrm{p}=.000$. Also confirmed by students' higher average score was students' positive affection towards research, with $\mathrm{F}(\mathrm{df})=80,291(1) ; \mathrm{p}=.000$. On average, students scored significantly higher on students' research (self)-efficacy, with $\mathrm{F}(\mathrm{df})=45,026(1) ; \mathrm{p}=.000$, as well as on students' intention to apply research in their future profession, with $\mathrm{F}(\mathrm{df})=22,918(1)$; $\mathrm{p}=.000$

On the second level of research activities, the mean scores of lecturers and students are more alike. Of the three scales, only students' interaction with researchers showed significant variation, with $\mathrm{F}(\mathrm{df})=32,337(1) ; \mathrm{p}=.000$. Lecturers also reported seeing more extracurricular research activities of students than students reported. The scales to read research and to be a researcher did not show significant differences between students and lecturers.

On the third level of research in the context of the students, significant differences were found on all three scales. Lecturers scored significantly higher on how they perceive the quality of research in the students' educational programmes, with $\mathrm{F}(\mathrm{df})=15,946(1) ; \mathrm{p}=.000$. However, students scored substantially higher on the research activities they perceive of their lecturers, 
with $\mathrm{F}(\mathrm{df})=136,002(1) ; \mathrm{p}=.000$, as well as how prominently they perceive the research culture of their university, with $\mathrm{F}(\mathrm{df})=33,519(1) ; \mathrm{p}=.000$.

\section{Discussion}

By combining the RAVE-Q and two additional scales expanded for lecturers, we developed a new measurement intended to compare lecturers' and students' perceptions of research integration in higher education. This instrument provides comparable measurements on three levels: (1) research attitudes (RAVE-Q), (2) integrated research experiences, and (3) research context.

The comparison of students' and lecturers' experienced research integration in a single and large university of applied sciences shows how the most substantial differences between these groups were found on research attitudes and research context. While students and lecturers indicate having similar perceptions on the position of research in students' future professions, other attitudinal differences call for more interaction between lecturers and students on the function of research within those professions. Lecturers showed higher scores on cognitive attitude and importance of research than students, which implies that lecturers think students have more positive views of the function of research as an important provider of new knowledge for professional action both during their education and when they are professionals. This provides lecturers with opportunities to engage with students about the function of research in relation to knowledge, which is a rather substantial topic of debate.

Additionally, students' higher scores on positive attitudes and self-efficacy, as well as lower scores on negative attitudes shows that students enjoy research activities more than lecturers think they do, which yields the risk of lecturers making research activities more 'fun' than needed for students. Apparently, students have a relatively positive stance towards research 
activities, although they could benefit from more serious debates on how research enhances knowledge.

In a way this is confirmed by the level 3 findings in which lecturers are more satisfied with the quality of research provided than the students are. Students feel less that they learn proper research practice and are less pleased with the quality of their research education. Students are also more positive about the research activities of their lecturers than lecturers themselves are. Students consider their lecturers much more as researchers than lecturers themselves do, which is interesting for an applied university in a higher education system that has only offered research funding since the turn of the century (Griffioen, 2018a; Huisman, 2008).

While the level 1 research attitudes and level 3 research context clearly provide angles for debate and improvement between lecturers and students, there were fewer differences between students and lecturers found on level 2, experienced research integration. Overall, the scores of lecturers and students were on the lower end of the scales, showing this applied university setting still lacks substantial research integration. The only difference found was that students perceive less interaction between students and researchers than lecturers do. It is important to note that, in this setting, lecturers are generally not research-active themselves, and so students would consider other researchers.

Overall, these results yield important data about the perceptions of students and lecturers, and most differences were found in attitudes and culture. Generally, debates on research integration tend to focus on research experiences (Verburgh \& Elen, 2011; Vereijken et al., 2016; Visser-Wijnveen et al., 2016), although recent work has shown that research attitude is mainly correlated to students' intention to use research in professional practice (Griffioen, 
2018b). Considering that our findings show that the differences between lecturers and students are also mostly related to research attitudes, this suggests the importance of lecturers explicitly discussing these differences with students and enhancing attitudes through curriculum design and classroom practice.

\section{Limitations}

Although the main aim of this study was to develop and test a questionnaire that can help higher education practitioners measure students' and lecturers' perceptions of research on three levels, the comparative findings of this study are rather generic. Hence, general validation of this questionnaire requires application in different settings, especially considering some limitations. The first limitation is the response ratio of the current study. While the sample sizes of both groups were relatively large and substantial enough for the current statistical purposes, the actual response ratio of the students was $6 \%$ and of the lecturers $10 \%$, which is too low for generalization. Application of the questionnaire to other samples of students and lecturers will add to the validation of the questionnaire.

Additionally, the current study focused on a comparison between students and lecturers on a university level with all undergraduate students and all lecturers considered as a single group. While the differences between students and lecturers found were rather substantial and informative, it is also clear that the university level also provides limitations (Vereijken et al., 2016; Visser-Wijnveen et al., 2016) and application of the questionnaire at the faculty or programme level would provide additional perspectives and validation. Other researchers have also considered the university level or cross-university level and drawn valuable conclusions (Verburgh \& Elen, 2011), so it would be even more interesting to have this questionnaire applied at multiple levels simultaneously and to indicate between-level differences in the perceptions of 
research integration. Finally, this instrument can provide university-change insights when applied in a longitudinal manner. Obviously additional qualitative measurements, such as interviews and observations, could provide important, deeper insights in this regard.

This study provided two types of insight: First, a measurement instrument to compare students' and lecturers' research attitudes, and second, the notion that the debate on research between students and lectures should become more extensive than only considering whether students experience a certain amount of research integration. To only consider whether students experience any research integration and not consider the rationale for involvement yields another perspective similar to Brew's (2006) critique that academics keep students out as serious players in the research game (see also: Bourdieu, 1988, p. 95-96). It is clear that by integrating many research activities into educational programmes, students are included in research as such. But only by actively discussing our underpinnings for doing so with students can they actually be included as partners. Only then will we provide them with the necessary tools to truly understand the importance we lecturers see in research as a provider of knowledge in both academia and the professions. It is high time that we not only provide meaningful research activities to our students but consider them as our true partners in the university. 


\section{References}

Ajzen, I., \& Fishbein, M. (2010). Predicting and Changing Behavior: The Reasoned Action Approach. New York: Taylor \& Francis.

Åkerlind, G. S. (2008). An Academic Perspective on Research and Being a Researcher: an Integration of the Literature. Studies in higher education, 33(1), 17-33.

Barnett, R. (2000). Supercomplexity and the Curriculum. Studies in higher education, 25(3), 255-265.

Barnett, R. (2012). Learning for an Unknown Future. Higher education Research \& Development, 31(1), 65-77.

Bourdieu, P. (1988). Homo Academicus. Stanford: Stanford University Press.

Bovill, C., Cook-Sather, A., Felten, P., Millard, L., \& Moore-Cherry, N. (2016). Addressing potential challenges in co-creating learning and teaching: overcoming resistance, navigating instutional norms and ensuring inclusivity in student-staff partnerships. Higher Education, 71, 195-208.

Brew, A. (2001). Conceptions of Research: A Phenomenographic Study. Studies in higher education, 26(3), 271-285.

Brew, A. (2003). Teaching and Research: New Relationships and their Implications for Inquiry-Based Teaching and Learning in Higher Education. Higher education Research \& Development, 22(1), 3-18.

Brew, A. (2006). Research and Teaching. Beyond the Divide. New York: Palgrave Macmillan.

Cook-Sather, A. (2014). Student-faculty partnership in exploirations of pedagogical practice: a threshold concept. International Journal for Academic Development, 19(3), 186-198.

Fung, D. (2017). A Connected Curriculum for Higher Education. London: UCL.

Gilardi, S., \& Lozza, E. (2009). Inquiry-Based Learning and Undergraduates' Professional Identity Development: Assessment of a Field Research-Based Course. Innovative Higher Education, 34, 245-256.

Griffioen, D. M. E. (2018a). Building Research Capacity in New Universities during Times of Academic Drift: Lecturers Professional Profiles. Higher Education Policy.

Griffioen, D. M. E. (2018b). The Influence of Undergraduate Students' Research Attitudes on their Intention for Research Usage in their Future Professional Practice. Innovation in Education and Teaching International. doi:10.1080/14703297.2018.1425152

Griffioen, D. M. E., \& De Jong, U. (2015a). Implementing Research in Professional Higher Education: Factors that Influence Lecturers' Perceptions. Educational Management Administration \& Leadership, 43(4), 626-645.

Griffioen, D. M. E., \& De Jong, U. (2015b). Mapping Dutch Higher Education Lecturers' Discourse on Research at Times of Academic Drift. Scottish Journal for Arts, Social Sciences, and Scientific Studies, 26(1), 81-94.

Griffioen, D. M. E., \& De Jong, U. (2017). The Influence of Direct Executive Managers on Lecturers' Perceptions on New Organizational Aims in Times of Academic Drift. International Journal of Leadership in Education(4), 451-467.

Griffioen, D. M. E., Groen, A., \& Nak, J. (submitted). The Integration of Research in the Higher Education Curriculum: A Systematic Review.

Healey, M., \& Jenkins, A. (2015). Linking Discipline-Based Research with Teaching to Benefit Student Learning Through Engaging Students in Research and Inquiry. Retrieved from http://www.mickhealey.co.uk/resources

Healey, M., Jordan, F., Pell, B., \& Short, C. (2010). The Research-Teaching Nexus: A Case Study of Students' Awareness, Experiences and Perceptions of Research. Innovations in Education and Teaching International, 47(2), 235-246.

Huisman, J. (2008). Shifting Boundaries in Higher Education: Dutch hogescholen on the move. In J. S. Taylor, J. Brites Ferreira, M. De Lourdes Machado, \& R. Santiago (Eds.), Non-University Higher Education in Europe. (pp. 147-168). Heidelberg | New York: Springer. 
Jenkins, A., \& Healey, M. (2005). Institutional Strategies to Link Teaching and Research. Retrieved from York:

http://www.heacademy.ac.uk/assets/York/documents/resources/resourcedatabase/id585_institutio nal strategies to link teaching and research.pdf

Karseth, B., \& Solbrekke, T. D. (2016). Curriculum Trends in European Higher Education, The Pursuit of the Humboldtian University Ideas. In B. J. T. S. Slaughter (Ed.), Higher Education, Stratifi cation, and Workforce Development. Competitive Advantage in Europe, the US, and Canada. (Vol. 45, pp. 215 - 233): Springer Science+Business Media.

Kline, R. B. (2011). Principles and practise of Structural Equation Modeling (3 ed.). New York, London: The Guiford Press.

Lopes, A., Boyd, P., Andrew, N., \& Pereira, F. (2014). The Research-Teaching Nexus in Nurse and Teacher Education: Contributions of an Ecological Approach to Academic Identities in Professional Fields. Higher Education, 68, 167-183.

Neumann, R. (1992). Perceptions of the Teaching-Research Nexus: A Framework for Analysis. Higher Education, 23(2), 159-171.

Pitcher, R. (2011). Doctoral Students' Conceptions of Research. The Qualitative Report, 16(4), 971-983.

Roseaux, B., Verachtert, I., Spooren, P., \& Van Petegem, P. (2014). The construction and validation of a mapping instrument for the research-teaching nexus in higher education. Paper presented at the Annual Conference of the Society for Research intro Higher Education, Newport, UK.

Schouteden, W., Verburgh, A. L., \& Elen, J. (2011). The use of drawings to assess lecturers' conceptions of research. Paper presented at the Americal Educational Research Association, New Orleans.

Schouteden, W., Verburgh, A. L., \& Elen, J. (2014). Teachers' General and Contextualised Research Conceptions. Studies in higher education. doi:10.1080/03075079.2014.914915

Smeby, J. C. (1998). Knowledge Production and Knowledge Transmission. The interaction between research and teaching at universities. Teaching in Higher Education, 3(1), 5-20.

Spronken-Smith, R., Mirosa, R., \& Darrou, M. (2014). 'Learning is an endless journey for anyone': undergraduate awareness, experiences and perceptions of the research culture in a researchintensive university. Higher education Research \& Development, 33(2), 355-371.

Tabachnick, B. G., \& Fidell, L. S. (2007). Using Multivariate Statistics. Boston: Pearson.

Teichler, U. (2014). On the Move Towards a New Convergent Design of Higher Education Systems. In J. C. Shin \& U. Teichler (Eds.), The Future of the Post-Massified University at the Crossroads (Vol. 1). Switserland: Springer International Publishing.

Trowler, P. R., \& Wareham, T. (2008). Tribes, Territories, Research and Teaching: Enhancing the Teaching Research Nexus. Retrieved from York: https://www.heacademy.ac.uk/resource/tribesterritories-research-and-teaching-enhancing-teaching-research-nexusliterature\#sthash.5NK7FyDy.dpuf

Van den Akker, J. J. H. (2003). Curriculum Perspectives: An Introduction. In J. J. H. Van den Akker, W. Kuiper, \& U. Hameyer (Eds.), Curriculum landscapes and trends (pp. 1-10). Dordrecht: Kluwer Academic Publishers.

Van der Linden, W., Bakx, A., Ros, A., Beijaard, D., \& Van den Berg, L. (2015). The development of student teachers' research knowledge, beliefs and attitude. Journal of Education for Teaching, 4l(1), 4-18.

Verburgh, A. L., \& Elen, J. (2011). The Role of Experienced Research Integration into Teaching upon Students' Appreciation of Research Aspects in the Learning Environment. International Journal of University Teaching and Faculty Development, 1(4), 1-14.

Vereijken, M. W. C., Van der Rijst, R. M., De Beaufort, A. J., Van Driel, J. H., \& Dekker, F. W. (2016). Fostering First-Year Student Learning through Research Integration into Teaching: Student Perceptions, Beliefs about the Value of Research and Student Achievement. Innovations in Education and Teaching International. doi:DOI: 10.1080/14703297.2016.1260490 
Visser-Wijnveen, G. J., Van der Rijst, R. M., \& Van Driel, J. H. (2016). A Questionnaire to Capture Students' Perceptions of Research Integration in their Courses. Higher Education, 71(4), 473488.

Visser-Wijnveen, G. J., Van Driel, J. H., Van der Rijst, R. M., Verloop, N., \& Visser, A. (2009). The Relationship between Academics' Conceptions of Knowledge, Research and Teaching - a metaphor study. Teaching in Higher Education, 14(6), 673-686. 
Table 1

Standardized Correlations Between Scales

\begin{tabular}{|c|c|c|c|c|c|c|c|c|c|c|c|c|c|c|c|}
\hline \multirow{8}{*}{ 离 - } & & & 1 & 2 & 3 & 4 & 5 & 6 & 7 & 8 & 9 & 10 & 11 & 12 & 13 \\
\hline & 1 & Perception & 1 & & & & & & & & & & & & \\
\hline & 2 & Cognition & .899 & 1 & & & & & & & & & & & \\
\hline & 3 & Negative Attitude & -.051 & 0 & 1 & & & & & & & & & & \\
\hline & 4 & Positive Attitude & .755 & .736 & -.272 & 1 & & & & & & & & & \\
\hline & 5 & Self-efficacy & .422 & .389 & .466 & -.339 & 1 & & & & & & & & \\
\hline & 6 & Intention & .800 & .749 & -.138 & .769 & .485 & 1 & & & & & & & \\
\hline & 7 & Importance & .648 & 645 & 0 & .565 & .294 & .577 & 1 & & & & & & \\
\hline \multirow{3}{*}{ 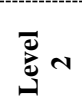 } & 8 & To read & .174 & .202 & 0 & .182 & .383 & .199 & .195 & 1 & & & & & \\
\hline & 9 & To interact & .158 & .180 & .099 & .189 & .247 & .191 & .159 & .692 & 1 & & & & \\
\hline & 10 & To research & .130 & .129 & 0 & .110 & .292 & .143 & .160 & .408 & .439 & 1 & & & \\
\hline \multirow{3}{*}{$\sum_{d}^{d} m$} & 11 & Quality education & .348 & .365 & -.130 & .339 & .558 & .329 & .196 & .522 & .281 & .402 & 1 & & \\
\hline & 12 & Lecturers' activity & .087 & .074 & 0 & .092 & .153 & .110 & .076 & .271 & .149 & .148 & .285 & 1 & \\
\hline & 13 & Research culture & .475 & .485 & -.059 & .515 & .442 & .486 & .528 & .445 & .399 & .434 & .621 & .218 & 1 \\
\hline
\end{tabular}

Note: All standardized correlations between factors (scales) in the final model. All correlations are significant at $\mathrm{p}<.01$. 


\section{Appendix A}

\section{Questionnaires for Students' and Lecturers Research Integration}

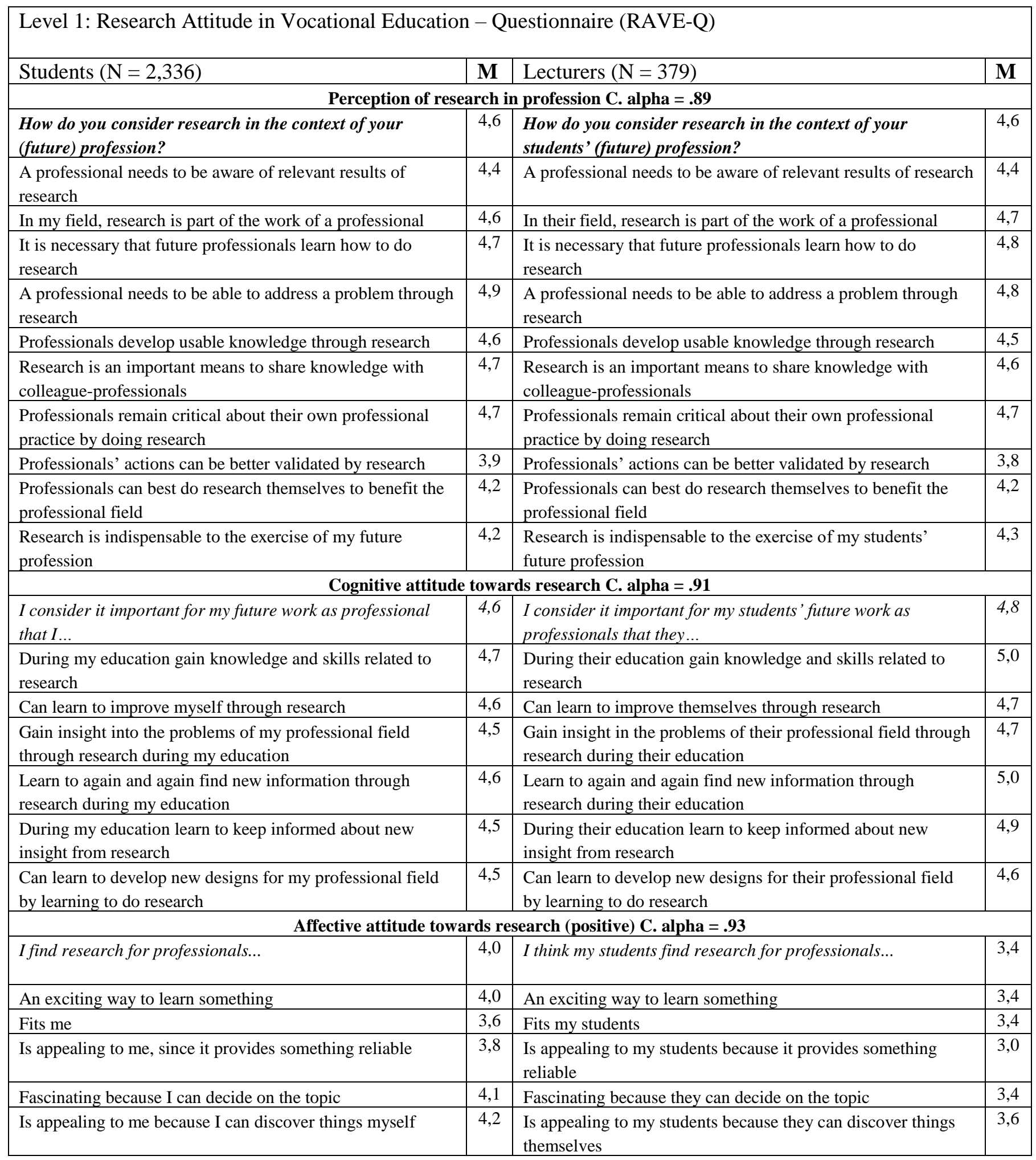




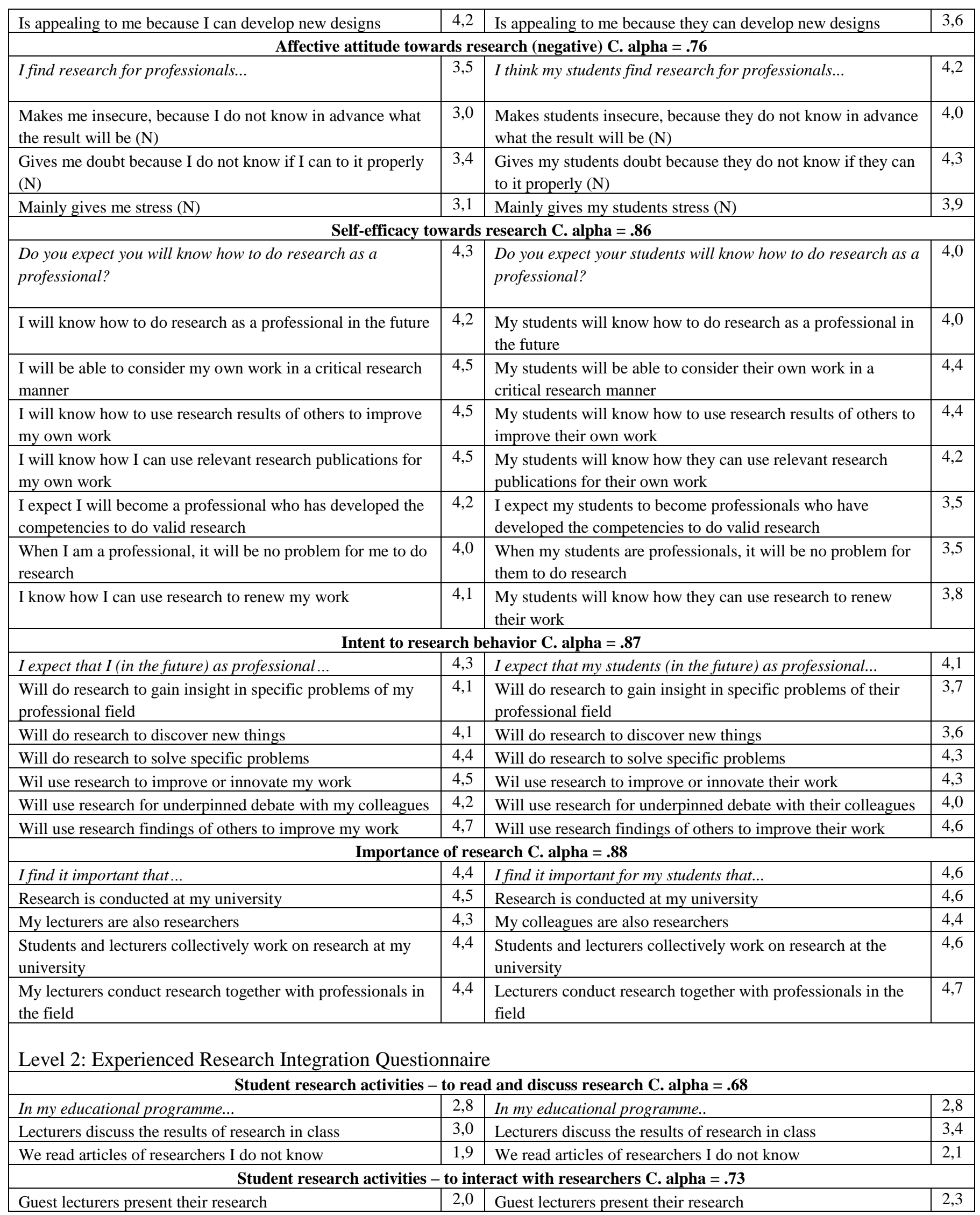




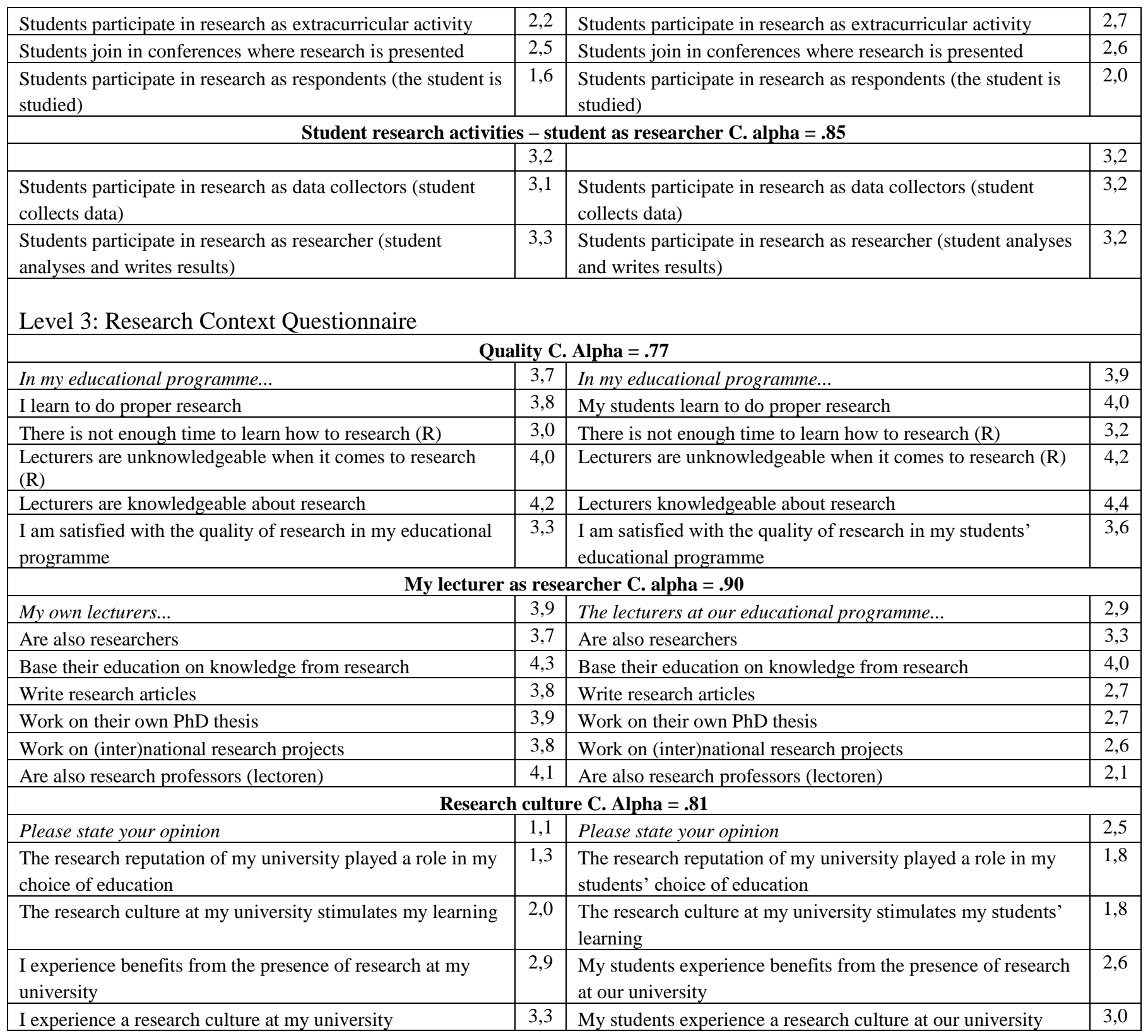

